\title{
The Financial Support Mode of Cultural Industry Development in Shaanxi Province
}

\author{
Wang Yushan \\ International Business School of Shaanxi Normal University \\ 812514478@qq.com
}

\begin{abstract}
As a province with plenty cultural resources, Shaanxi develops cultural industry in a sustainable and highquality manner, and turns itself into a strong cultural province, which is inseparable from the support of the finance. This paper subdivides the cultural industry in Shannxi province into five categories: radio, film and television, news and publishing, cultural tourism, cultural performance and cultural and creative industries. In accordance with the characteristics of various industries, this paper also sorts out the financial needs of various industries separately and reveals the financial support.
\end{abstract}

\section{Keywords-Culture industry; Financial support}

\section{INTRODUCTION}

Chinese culture has a long and abundance history. The culture status of Shaanxi is important as one of the birthplaces of Chinese traditional culture. In recent years, in order to give full play to the important role of cultural industries in the economic and social development, Shaanxi Province takes many major measures to accelerate the development of cultural industries. The province's cultural industry has shown an accelerated development trend in recent years. In 2016, Shaanxi Provincial Performing Arts Group performed 39,000 games; the audience was 32.41 million; the province's library collection was 16.26 million; the book read literature borrowed a total of 411 times, 7.07 million copies (Table 1); in cultural sports and media A total of 12.55 billion yuan was spent, an increase of $34.36 \%$ over the previous year (Table 2 ).

TABLE I

Development of cultural undertakings in 2005-2016

\begin{tabular}{|c|c|c|c|c|}
\hline Year & $\begin{array}{c}\text { Artistic group } \\
\text { performances }\end{array}$ & Audience & $\begin{array}{c}\text { Number of books in the } \\
\text { library }\end{array}$ & Book borrowing times \\
\hline 2005 & 2.2 & 1916 & 887 & 136 \\
\hline 2006 & 2.2 & 4020 & 913 & 182 \\
\hline 2007 & 2 & 1918 & 936 & 181 \\
\hline 2008 & 2 & 1905 & 1002 & 214 \\
\hline 2009 & 2.1 & 2391 & 1059 & 190 \\
\hline 2010 & 1.8 & 3093 & 1127 & 216 \\
\hline 2011 & 1.9 & 1822 & 1223 & 299 \\
\hline 2012 & 2.3 & 2418 & 1400 & 335 \\
\hline 2013 & 2.5 & 2681 & 1377 & 354 \\
\hline 2014 & 2.4 & 2110 & 1514 & 389 \\
\hline 2015 & 3.4 & 4322 & 1506 & 411 \\
\hline 2016 & 3.9 & 3241 & 1626 & \\
\hline
\end{tabular}

TABLE II $\quad$ Financial expenditures of cultural sports and media in Shaanxi Province from 2007 to 2016

\begin{tabular}{|c|c|c|c|c|c|c|c|c|c|c|}
\hline Years & 2007 & 2008 & 2009 & 2010 & 2011 & 2012 & 2013 & 2014 & 2015 & 2016 \\
\hline $\begin{array}{c}\text { Expen } \\
\text { ditures }\end{array}$ & 21.73 & 31.81 & 40.89 & 40.89 & 47.86 & 61.27 & 91.81 & 100.44 & 93.23 & 125.5 \\
\hline
\end{tabular}

However, there are still many serious problems in the current development of Shaanxi cultural undertakings. Although cultural resources and science and technology education have strong comprehensive strength and belong to cultural resources and strong science and technology provinces, the combination of cultural resources and market is still shallow, which seriously hinders and restricts the advancement of Shaanxi's cultural production. 


\section{TYPES OF CULTURAL INDUSTRY AND THE} DEVELOPMENT OF MAJOR CULTURAL INDUSTRIES IN SHAANXI PROVINCE

\section{A. Broadcasting and film industry}

The broadcasting and film industry is an important branch industry in the cultural industry. It has a large influence, a wide audience, and a relatively good financial foundation. The radio, film and television industry is a breakthrough in accelerating the development of cultural industries in Shaanxi.

The development of the broadcasting and film industry in Shaanxi Province first needs to let financial institutions have a basic understanding of the industry development and policies, and timely know the information of key enterprises and key projects to prepare for financial institutions; enterprises can sign with financial institutions such as banks. Cooperation agreements and maximize the scale of freight forwarding, obtain financial support, and encourage enterprises and financial institutions to cooperate on specific projects.

The government must also give a certain degree of policy encouragement and financial subsidies. At present, most radio and television companies in various regions have cooperated with banks, and some banks also provide special credit lines for cultural enterprises. Through mergers and acquisitions and reorganizations such as public issuance, private placement and other forms of refinancing, qualified broadcast and film companies can issue corporate bonds, collective bonds and corporate bonds, and insurance companies can also invest in bonds and equity of broadcast and film companies.

\section{B. News publishing industry}

In recent years, the news and publishing industry in Shaanxi Province has continuously deepened its reforms and has maintained a rapid and steady trend in its development trend. There are 18 book publishers in Shaanxi, 9 audio-visual electronic publishers, 87 newspapers, 268 journals, 1 publishing group, 1 publishing group, 4228 printing companies, and 3,454 publishing and publishing companies. There are more than 100,000 people. In 2016, there were 268 kinds of magazines in Shaanxi Province, with a total of 30.67 million copies and 190.713 million copies. There were 43 kinds of newspapers, with a total of 536.82 million copies and $159,970,000$ copies. It has formed an industrial system with complete links and various economic systems.

The press and publication industry is a traditional industry in the cultural industry, and the number of small and mediumsized companies is large. In recent years, the impact of the Internet and new media has been great. The operating conditions of most companies are worrying. Many companies are under pressure to close down, leaving only a few large companies. At present, although China has a certain degree of special support for the news and publishing industry, but various ways are mixed, and have not explored a unified and efficient model. In addition, there is government support, sometimes the intensity is slightly insufficient, and the press and publication industry has not received effective financial support.
Financial institutions should actively explore the pledge of copyright, pledge of accounts receivable, pledge of warehouse receipts, pledge of art management rights, supply chain financing, merger financing, financial leasing and other loan types, and gradually expand the scope of application of pledge loans for intangible assets. For news publishing companies with large financing scales and many projects, they can try syndicated loans; for small and medium-sized news publishing companies, they can try to jointly protect joint loans. Financial institutions can encourage large publishing media groups to issue corporate bonds, corporate bonds, collective trusts, and collective bonds. Encourage qualified small and medium-sized news publishing companies to issue medium-term notes, shortterm financing bonds, and collections of small and mediumsized enterprises.

\section{Cultural tourism}

Since the reform and opening up, the tourism industry, which is known for its history and culture, has always been a pillar industry in Shaanxi. In 2016, the province received a total of 449.13 million domestic and foreign tourists, with an average annual growth rate of $16.45 \%$. Among them, the total tourism revenue totaled 381.3 billion yuan, with an average annual growth rate of $26.85 \%$, both exceeding the national average development level. With the continuous development of the economy, the integration of culture and tourism has gradually become a new driving force for the development of cultural industry in Shaanxi. The construction and investment period of the cultural tourism industry is long, and the demand for investment is large, which makes industrial financing more difficult. Most of the current investments are indirect investment, and direct investment is relatively small; the products are relatively single, that is, short-term working capital based on project mortgage. Lack of long-term stable investment funds as industrial development support.

The financial industry can optimize the total amount and structure of credit from the following aspects, and the tourism industry will coordinate development. First, we must explore various credit models to improve the ability and efficiency of credit allocation across the industry chain. Explore the "policy finance + commercial finance" cooperation model to compensate for market failures. The second is to customize the "credit+" support model of "tourism+" from the perspective of the entire industry chain to improve the effectiveness of financial support.

\section{Artistic performance industry}

The art performance industry is a cultural and artistic industrial structure with geographical advantages in the cultural industry of Shaanxi, and it is also one of the key development projects of the cultural industry in Shaanxi Province. In recent years, Shaanxi Province has fully utilized the role of market rules and economic leverage, changed funding methods, tilted to performances, increased support for artistic performances, and guided performance groups to the market.

Due to the characteristics of the cultural performance industry, it is often necessary to have a relatively stable longterm investment to ensure the sustainable development of cultural performances. Commercial banks can set up a cultural 
industry finance department, focusing on providing innovative financial services to the performing arts industry, achieving long-term tracking and docking; financial institutions (banks, trusts, guarantee companies, etc.) launch a series of innovative products based on the characteristics of cultural industry enterprises. For example, patent pledge, copyright pledge, trademark pledge, and so on. And tailor the credit approval process, guarantee system and loan model for cultural enterprises.

\section{E. Cultural and creative industry}

Xi'an gathers more than $70 \%$ of the institutions, personnel, facilities and economic strength of the two levels of creativity in the province and city, making it the most important industrial cluster and industrial center for the future Chinese cultural and creative industries. The fundamental development of the cultural and creative industry still needs to rely on the local cultural characteristics. The types of enterprises in the gathering area are single, and the number of enterprises is small, and the proportion of small enterprises and individual cultural workers is relatively low.

The cultural and creative industries belong to the emerging cultural industry. The development of the industry is not stable enough and there is no stable consumer group. Most cultural industries rely on government and investor investment, and the capital chain is not strong enough. The cultural and creative industries need some fixed and sustainable financial support. The use of funds is not only used for the operation and construction of the cultural and creative industries, but also for the creative development of products and the maintenance of product patents, in order to maintain the innovation of continuous products and fundamentally enhance the benefits. And for some cultural performance projects and cultural and creative products, we can introduce crowd funding models, attract social funds, enhance the visibility of enterprises and products, ease corporate financial pressure, and diversify investment risks.

\section{CULTURAL AND FINANCIAL INTEGRATION}

The dual attributes and dual benefits of cultural products enable financial capital and cultural industries to naturally integrate and help each other. Cultural products have dual attributes, namely social ideology attributes and commodity attributes. The ideological attribute of cultural products determines that it emphasizes social benefits, and should reflect the development requirements of the times and the fundamental interests of the people; the commodity attributes of cultural products require it to follow the law of value, calculate input and output, and emphasize economic benefits. The commodity attributes and economic benefits of cultural products can attract the active investment of financial capital, and through the instigation of financial capital, accelerate the realization of cultural industry agglomeration and economies of scale, thereby further embodying the cultural ideological attributes and enhancing social benefits.

At present, there are five types of domestic cultural financing methods, including government grants, bank loans, listing financing, venture capital and bond financing. The main problems of cultural and financial integration in Shaanxi Province are small financing, relatively low coverage, large regional differences, imperfect basic supporting systems for cultural and financial cooperation, and insufficient innovation in products and services for commercial banks to support the development of cultural industries.

When financial capital participates in the cultural industry, most of them adopt a prudent attempt and lack mature and perfect top-level design. At the same time, it is often difficult for financial institutions to accurately grasp the commercial value and comprehensive benefits of cultural and creative enterprises, which in turn affects the willingness to support funds. At present, the construction of the system and the legal system is still not perfect. For example, intellectual property protection, asset valuation, and capital circulation are still in need of improvement. The construction of cultural and financial intermediation systems such as copyright appraisal institutions, guarantee institutions, custody and agencies is relatively lagging behind. It does not function as a "bridge" for communication between cultural enterprises and financial institutions. It is difficult for financial institutions to evaluate, transfer and dispose of cultural assets. The financial products and service models are relatively simple, the supply of cultural and financial professionals is relatively insufficient, and emerging technologies such as big data, Internet and artificial intelligence have not been effectively applied, and cultural and financial services and management levels are relatively backward.

\section{CONCLUSION}

In the financial support for the cultural industry, there are few funding channels and lack of relevant regulatory measures, which makes it difficult for capital to flow into the cultural industry. The expected benefits of the cultural industry are difficult to estimate, the products are not practical enough, and private capital is difficult to enter, forming a vicious circle. However, as the income of the cultural industry has grown greatly, investment in the cultural industry has increased. It turns out that there are enough capitals to fund the cultural industry, but many of them have no suitable channels to stop, the channels are not smooth, information the phenomenon of asymmetry is very serious. Today, Shaanxi Province should pay attention to setting up special supervision mechanisms and measures for financial subsidies in the cultural industry, and provide sufficient and sufficient financing channels to make private capital easier to enter the cultural industry.

Although Shaanxi Province has focused on the development of cultural industries in recent years, it is mainly inclined to the cultural leisure and entertainment service industry. It has less investment in old industries such as press and publication, radio and film, and does not pay much attention to cultural creativity and design services. The development of the industry relies mainly on the source of cultural development, that is, the creativity and design of culture, and innovation, and innovation based on the inherent traditional culture is an important measure to make the cultural industry sustainable. In order to make Shaanxi Province a true cultural province, it is necessary to provide sufficient financial support for cultural creativity and design. 


\section{REFERENCES}

[1] Qin Zhili.Research on the Problems, Causes and Cracking Path of Cultural Industry Financing__Based on Data Analysis in Western Regions[J].Time finance,2017(29):49-52.(In Chinese)

[2] Wang Wenna.The Basic Logic of Financial Innovation in Cultural and Creative Industry in Shaanxi Free Trade Zone[J].Time Finance,2017(23):105-106.(In Chinese)

[3] Li Wang.Research on the Development of Cultural Industry by Financial Innovation Tools[J].Chinese Culture,2017(11):73-75. (In Chinese)

[4] Zhu Jiajun,Wang Min.Research on the Development Model and Operation Mechanism of Cultural and Financial Cooperation Zone[J].Business of Jiangsu,2017(06):54-57.(In Chinese)

[5] Zhang Zhiwei, Shi Yao.Thoughts on the Construction of Cultural Financial Service System[J].Journal of Xihua University (Philosophy and Social Sciences Edition),2017,36(03):66-70+98.(In Chinese)

[6] Gao Tiancheng.Two-way promotion strategy of Shaanxi cultural industry development and city brand image[J].Journal of Xi'an University of Arts and Science (Social Science Edition),2017,20(01):98102.(In Chinese)

[7] He Xiaoxia.Analysis on the Connotation of Policy Innovation of Cultural and Creative Industry[J].Enterprise reform and management,2016(16):178.(In Chinese)

[8] Zhu Jiliag.Environmental Analysis and Path Selection of Cultural and Creative Industry Development in Xi'an City[J].Scientific and technological progress and countermeasures,2014,31(19):46-50. (In Chinese) 